Note: This is the author pre-print version of this article. The final version of this article was published as:

Karvonen, Andrew and Bas van Heur. 2014.Urban Laboratories: Experiments in Reworking Cities, International Journal of Urban and Regional Research 38(2) 379-392,

doi: $10.1111 / 1468-2427.12075$

http://onlinelibrary.wiley.com/doi/10.1111/1468-2427.12075/abstract

\title{
Urban Laboratories: Experiments in Reworking Cities
}

\section{Andrew Karvonen and Bas van Heur}

\begin{abstract}
The notion of urban laboratories is increasingly striking a chord with urban actors who are pursuing radical change in cities. Experimentation is seen to be helpful in realising environmental sustainability, economic development, social equity, and cultural progress. But is the 'urban laboratory' term simply a metaphor for conventional urban development or does it constitute urbanisation by another means? In this article, we review the work of science and technology studies (STS) scholars who have studied laboratories over the past three decades and apply their insights to contemporary notions of urban laboratories and its emphasis on experimentation in knowledge production. We argue that experimentation is predicated on three achievements of urban laboratories: situatedness, change-orientation, and contingency. These three achievements are helpful in evaluating and critiquing contemporary urban laboratories and clarify how processes of laboratorisation are useful in opening up urban development to new modes of thought and action.
\end{abstract}

\section{Keywords}

Urban laboratories, laboratory studies, experimentation, situatedness, changeorientation, contingency 


\section{Introduction}

On August 3, 2008, the Associated Press published a news article about China's Summer Olympic games titled 'Pollution curbs turn Beijing into urban laboratory'. The article (Associated Press, 2008) summarises the massive efforts to clear up the perennially polluted skies of the city as follows:

In what scientists are calling the single largest attempt ever made to improve air quality, scores of heavily polluting factories were shut down and some 2 million vehicles were pulled off roads across Beijing and a huge swath of northern China - an area roughly the size of Alaska. During the weekend, the hazy skies finally gave way to swirling blue. Beijing's massive experiment with controlling pollution is offering international researchers a one-of-a-kind chance to study the large-scale effort in a uniquely urban laboratory.

This experimental intervention to reduce air pollution in Beijing is a widely publicized example of how the notion of 'urban laboratory' is emerging in multiple settings around the globe. From Toronto and Dallas to Glasgow and London, from Berlin and Hong Kong to Ethiopia and Curitiba, interpreting the city as a laboratory seems to be increasingly striking a chord with actors involved in urban change. It champions the promise of experimental processes in cities to promote innovative efforts related to environmental protection, social cohesion, capitalist expansion, creative sector development, policy improvements, infrastructure provision, academic research, and so on. But is this use of the term 'urban laboratory' simply another metaphor for urban development or does it suggest urbanisation by significantly different means?

The aim of this symposium issue is to explore the various ways that urban laboratories are being conceived, constructed, and practiced in contemporary cities while also proposing a more critical lens to assess these activities. In other words, the goal is to move from metaphor to analysis by unpacking the notion of 'laboratory' and understanding how it is helpful in framing and catalysing urban change. To enable such an analytical approach, it is important to recognise that the notion of urban laboratory as employed in urban development initiatives is related to a wider discursive field that includes ideas of Mode 2 Science, triple helix formations, engaged research, service learning, transdisciplinarity, living laboratories, applied innovation, and the coproduction of knowledge (Benneworth et al., 2010; Evans and Karvonen, 2011; Gibbons et al., 1994; Nowotny et al., 2001; Ramadier, 2004). Bruno Latour is one of the most well-known proponents of this broad understanding of laboratories and experimentation; he (2001: 1) writes, 'that we are all engaged into a set of collective experiments that have spilled over the strict confines of the laboratories does not need more proof than the reading of the newspapers or the watching of the night TV news.' While we do not have the space to discuss the overlaps and conflicts between these various notions of innovation, risk, and knowledge production, there is an important link with interpretations of urban development as a collaborative, interdisciplinary process, as a data-intensive research activity, and as context-specific trial-and-error interventions. In other words, it taps into ideas of urban change as inherently multidisciplinary, data intensive, and embedded in place. 
In this article, we begin by reviewing how the concept of the laboratory has been unpacked in the last three decades by scholars in science and technology studies (STS). Laboratory studies scholars have reinterpreted these privileged sites of knowledge production by tracing how scientific insights travel back and forth between the laboratory to society. Another key aspect of laboratory studies - experimentation - is central to the notion of urban laboratories and is the focus of the next section. We argue that experimentation is helpful for opening up the evolution of cities to new conceptions and configurations; the nurturing of innovation in a particular place - a laboratory opens up urban change to risk and the potential for failure. The emphasis on experimentation leads to three achievements of urban laboratories: situatedness, change-orientation, and contingency. Using these three achievements as normative benchmarks, we can then evaluate and critique those practices that claim to be urban laboratories. To conclude, we consider some future directions of research on urban laboratories.

\section{Unpacking the Notion of Laboratory}

Laboratory studies began in earnest in the late 1970s and today, this scholarship serves as the foundation for the contemporary field of STS. Laboratory studies researchers were inspired by the emerging notion of the social construction of scientific facts as well as various philosophies of scientific and technological knowledge production. Early laboratory studies served to deconstruct the objective claims of scientists by contextualising scientific practice to emphasise the interests, techniques, materials, and discourses involved in the stabilisation of supposedly neutral scientific facts. ${ }^{i}$ They debunked the notion that scientific knowledge production was apolitical, asocial, and universal by exposing the myth of laboratories as 'special places from which pure knowledge emanated' (Doing, 2008: 279). This opened the laboratory practices of natural scientists to critical scrutiny by social scientists as well as policymakers and the general public.

A key outcome of the contextualisation of scientific 'facts' was that laboratories were made to look less special and more commonplace; the laboratory was no longer a privileged site of knowledge production but became one site among many. This has had a number of research consequences. First, historians of science in particular began to investigate the heterogeneity of laboratories. Whereas the twentieth-century modern laboratory was understood to be 'set apart' from the surrounding natural and social world (an idealistic representation effectively deconstructed by laboratory studies), other laboratories often operated with less rigid distinctions and effectively meshed scientific research with artisanal, commercial, and other forms of non-laboratory practice (Galison and Thompson, 1999; Gooday, 2008; Klein, 2008). Second, STS scholars closer to the tradition of sociology increasingly interpreted the laboratory as a theoretical notion. Latour argues that the focus should be less on what happens inside particular laboratories and more on how laboratory practices are extended throughout society, in effect 'transforming society into a vast laboratory' (1983: 166). He proposes three steps to achieve this transformation: first, scientists have to capture the interests of non-scientists outside of the laboratory (the field); second, they have to collect information on 'real-world' problems in the field and introduce this information into the 
controlled conditions of the laboratory to facilitate experimentation; and third, scientists have to extend the laboratory to wider society by carefully re-introducing the experimental results back into the field. From Latour's perspective, the laboratory becomes a mechanism of control and distribution: it is through the strategic negotiation between inside and outside that the laboratory exerts its societal power. A similar conceptualization of this process of 'laboratorization' is offered by Karin Knorr-Cetina, who argues that the laboratory is an "enhanced" environment that "improves upon" the natural order as experienced in everyday life in relation to the social order' (1995: 145). This follows the laboratory studies emphasis on the natural sciences, but Knorr-Cetina also argues that laboratories 'upgrade' the social order (146) and makes the grander claim that research should analyse 'processes of laboratorization' in a much wider variety of settings (163).

The effects of opening the laboratory to the world has had mixed results. Arguably the most positive effect has been to critique the status of the scientific laboratory as a privileged site of knowledge production. In essence, the laboratory has been invaded by the outside world and conversely, the outside world has been invaded by the laboratory. However, the ethnomethodological and situational focus of most laboratory studies creates a type of research that prioritizes the in situ analysis of science in practice at the expense of ex situ institutional elements that shape the direction and substantial content of these practices (Sismondo, 2004). In the context of urban studies, laboratory studies are helpful for describing the contingent dynamics of particular scientific sites, but less useful in analysing the broader organizational and institutional features that play a central explanatory role in the development of cities. It privileges laboratories as the locus of power while overlooking other institutional and cultural sources of knowledge production.

Laboratory study scholars have also been helpful in blurring the distinction between the laboratory and the field. In his work on labscapes, Robert Kohler (2002a; $2002 \mathrm{~b}$ ) shows how laboratories played a strategic role in the discipline of biology. On the one hand, laboratories are seen as the perfect placeless sites that 'enable biologists to study natural objects - organisms - on experimenters' terms, not nature's, free of all the messy complications of life as it is actually lived in a crowded and changeable world in which everything is related to everything else' (2002a: 473). It is this supposed placelessness of laboratories that gives the produced knowledge a universal quality. On the other hand, empirical research shows that this isolation from the outside world is an illusion, a social construction that allows for the regulation and control of traffic of people, natural objects, and instruments between inside and outside. In practice, laboratories are constantly re-embedded in and connected to their wider milieu and Kohler discusses various types of laboratories - marine biological stations, field stations, vivaria, and biological farms - that have undergone processes of 'naturalization'. A similar point is made by Christopher Henke in his research on agricultural field trials. As Henke (2000: 490) writes, '[f]ield trials combine the control of experimentation with the unique particularities of a given place. This combination gives them epistemic authority [...] but also makes field trials hard to control.' What is at stake is not the distinction between laboratory and field but the ways in which the laboratory vocabulary and associated practices enable a strategic ordering and 
regulation of uncontrollable field conditions. One way to bring the insights of laboratory studies to urban studies is to emphasise the importance of place and to examine the emergent tensions between control and lack of control, between uniqueness and generalisation, between contingency and universality (Gieryn, 2006). Laboratories offer a tool to mediate these dichotomies.

\section{The Promise of Experimentation}

An unfortunate consequence of unpacking the epistemology of laboratory practices has been the obscuring of the practice of experimentation. Early laboratory studies are partly to blame because the focus on the actors, technologies, instruments and materials leads to a contextual focus that often muddies what exactly constitutes experimentation. Subsequent applications of the laboratory vocabulary to nonlaboratory contexts have led to a further neglect of the specific contribution of experimentation to knowledge production. This is particularly the case in urban studies, where a metaphorical usage of the notions of laboratory and experiment seems to be the norm rather than the exception. In a recent editorial, for example, Gail Davies (2010: 667) rightly identifies that once the 'laboratory overspills its traditional constitution', it changes 'the very idea of an experiment, and the question of how and where experiments end.' But her subsequent discussion does not help to answer this question, since almost everything now qualifies as an experiment, or at least all actions that 'engage with the transformation of spatial and temporal description, the framing of possible actions, and the preformatting of subject/object relations' (668). The discussion is so broad that it allows Davies to talk about experimental interventions, experimental sites, experimental experience, the body as experimental site, experimental geography, experimental aesthetic, alternative experimental knowledges, and experimental landscapes without identifying the characteristics that make experimentation different from action or agency. Similar problems arise when social theorists such as Latour (2001; 2004) and Ulrich Beck (1995) characterise contemporary social change as 'collective experiments' or a 'global experiment'. These ideas are thought provoking on a general level but the terminology of experimentation is emptied of meaning and becomes frustratingly imprecise when applied to empirical research. Matthias Gross (2010: 66) rightly issues a cautionary warning on the increasing embrace of experimentation by social theorists, because the concept of experimentation comes to have the same meaning as development, complexity, interconnection, globalisation and so comes to mean the same as virtually anything that is subject to change.'

Rather than conflating 'experimentation' with 'change' and claiming that everything is an experiment, there is a need to adopt a precise understanding of the practice of experimentation. Returning to the laboratory studies scholarship, it is helpful to understand experimentation as (1) involving a specific set-up of instruments and people that (2) aims for the controlled inducement of changes and (3) the measurement of these changes. These aspects of experimentation are not essential characteristics; they are mutually constitutive of material and conceptual work. Moreover, failure in achieving these aspects is just as likely as success. An experimental set-up involves not only the identification of objects to be observed, but also the design, 
construction, and use of instruments to manipulate these objects. It is an open question to what extent these instruments dictate the experimenter's actions and how experimenters shape the very configuration and use of particular instruments (Gooding et al., 1989: 1), but the key point is that experimentation always involves a double move of observation and intervention. Many things can be or become instruments and STS researchers have investigated everything from the telescope, the barometer, and the common glass prism to brain imaging scans and neutrino detectors. These instruments are commonly understood as neutral transmitters of the hidden truths of nature but in actuality, a great deal of work is done 'to establish the character of an object as an instrument' and 'to win the assent of a community to the object's reliability and transparency' (Gooding et al., 1989: 3). One important route through which this assent is established is through the creation of standards according to which these instruments are designed, constructed, and used. Fixing the identity of particular instruments closes down discussion; the instruments are legitimized (people accept the instrument as a transmitter of observational data) and become replicable (in fixing standards, people can use these instruments elsewhere in similar ways).

Experimentation also involves the constant shuttling between local and nonlocal dimensions of concepts and theories. Experimental laboratory work is underpinned by various assumptions ranging from research questions to background knowledge, systematic theories, and topical hypotheses (Hacking, 1992). This constitutes the non-local aspect of experimentation since most of these concepts and theories have emerged elsewhere and are being applied to a new situation. At the same time, experimentation has to be understood as profoundly localized - as taking place in and through a certain place - but in a seemingly paradoxical way. It is through situated experimentation that non-local concepts and theories emerge. This is not recognized by authors such as Latour. In his early laboratory studies work with Steve Woolgar, Latour defends a position of 'strict localism' by claiming that local laboratory conditions account for the identification and even existence of particular phenomena. Hans Radder (1996: 88) argues that this 'makes it a complete mystery how and why scientists from different local contexts come to agree on issues of reproducibility, as they frequently do'. The later work of Latour on Actor Network Theory (ANT) addresses this problem by arguing that reproducibility is achieved through processes of translation and extension - Latour's three-step analysis discussed above fits this type of argument. But this approach merely creates new problems, since the original and the new context always differ in some respects. Most importantly, it ignores that the same experimental results can be achieved with different experimental processes and that concepts are often applied to dissimilar observations (Radder, 2006: 148). Indeed, as an example of the latter, what could be more dissimilar than trials in the natural sciences and urban development projects? Nevertheless, both processes are described with the vocabulary of experiments and laboratories because some actors feel this resonates with their experiences on the ground. This points to the need to move beyond the network-centric nature of ANT and to recognize the ways in which the 'conceptual-theoretical dimension' of scientific labour transcends 'its technological dimension of material realization' (Radder, 2006: 148-149). In effect, such a move allows for a much stronger future-oriented and normative approach than ANT, since the application of new 
concepts and theories to particular situations can contribute not only to new meanings but also to new ways of doing things (i.e. to ontological emergence and novelty) (Radder, 2006; van Heur, 2010).

Furthermore, the use of concepts and theories plays an important role in communicating experimental results to other actors within and beyond the locality. This involves the communication of 'objective' research results but it also opens up communication to rhetoric. Theories are underdetermined; actors have to be persuaded to accept and apply them to their own work (Cantor, 1989). We see the popularity of phrases such as 'urban laboratories' and 'urban experiments' as tapping into this rhetorical dimension of experimentation. This directs our attention to particular narrative strategies and language forms as well as new practices of presentation. Experiments, as laboratory studies scholars have investigated in detail, are always public engagements: it is through demonstrating an experiment in public that particular audiences are persuaded (Shapin and Schaffer, 1985). In the current era of 'post-Fordist science' (Gieryn, 2008), persuasion is realised in the design of the built environment, with urban laboratory projects regularly accompanied by iconic architectural statements and persuasive branding strategies. This suggests that public experiments need to be explained with reference to economic as well as epistemic rewards.

\section{Urban Laboratories and Experimentation: Three Achievements}

In extending the concepts of laboratory and experiment from the natural sciences to the city, the key question should not be if one can understand cities as laboratories in which experimentation takes place. Previous urban studies researchers have already appropriated this vocabulary in order to describe urban development processes. Most famously, the Chicago School sociologists argued in the early twentieth century for the need to understand the city as a social laboratory and their main research site - Chicago - as an experiment in social research (Park, 1929). According to Robert E. Park, the emergence of cities had led to a 'new social order' that is 'neither absolute nor sacred, but pragmatic and experimental' (1929: 3) and this is what radically distinguishes the city from the countryside. In his conceptualization, the city operates both as the site for experiments and as a cognitive frame of reference through which 'observations of social conditions' can be controlled (11). What makes the city experimental is the ways in which these observations are linked to policy intervention and reform: the assumption is that 'more complete knowledge' of people and urban areas can support social agencies in dealing with and solving social problems (15). As Joseph Heathcott (2005) has described in his study of the US planner Harland Bartholomew (who also interpreted the city as a laboratory), this emphasis on the need for complete and objective knowledge on the city through the systematic investigation of its parts was shared by most planners in the early to mid-twentieth century, but this ignored the extent to which moral visions, theoretical discourses, political struggles, and positionalities of the researchers shaped the knowledge being produced.

Considering these previous usages, the question becomes what the vocabulary of laboratories and experimentation - the updated version that is as it has become rephrased through the debates in STS - adds to our understanding of urban change. In using this new-old terminology, what can we see that we otherwise would not see? In 
our view, urban laboratories involve three key achievements: situatedness, changeorientation, and contingency.

Urban laboratories are best understood as constructed sites of knowledge production. They are constructed because the very identification of a city or section of a city as a laboratory necessitates substantial conceptual and material work. It involves the making of a distinction between what is and what is not part of the space of the laboratory. In order to stabilize this distinction between the laboratory and the field, resources, data, and actors need to be channelled and controlled in an orderly manner. As discussed above, this ordering can take place through the strategic use of particular instruments, techniques, standards, concepts, and theories. Gieryn (2006) has shown how the Chicago School researchers construed the city as both laboratory and field site to capitalize on the scientific credibility of both terms. Most famously, they claimed to approach the city as a laboratory: a controlled environment open to scientific observation and manipulation to produce universally valid research results. At the same time, the city was understood as a field site that was already situated and exhibiting its own locally specific dynamics. The urban laboratory, in other words, is then both a place and a non-place and much of the work that goes into constructing the laboratory revolves around mediating this tension. As Henke and Gieryn (2008: 359) argue, 'legitimate knowledge requires legitimizing places' and in the case of urban laboratories, this involves the production of knowledge that will be recognized as valid by local as well as non-local audiences. With respect to the current global emphasis on innovation and transformative urban strategies, the label of 'urban laboratory' legitimises experimental practices within prescribed boundaries. The requisite placeness of urban laboratories offers a material focus for certain actors to ascribe visions of alternative futures that are also globally recognized.

In the contributions to this symposium, the cognitive and material situatedness of the urban laboratories is central. In their study of the low carbon urban laboratory in Manchester, James Evans and Andrew Karvonen demonstrate how influential property owners defined a shared space of innovation where they could combine their investments in future development. Govind Gopakumar's analysis of the rollout of water supply infrastructure in Bengalaru, India recognises how these networks inscribe a distinctive space in the city but one that is constantly in flux due to negotiations between formal and informal actors. Philipp Dorstewitz's study of Zollverein in Essen, Germany demonstrates how an abandoned industrial site served as a durable foundation upon which experimental urban development could be conducted. Barbara Allen's study of green building activities in post-Katrina New Orleans are shaped not only by the destructive aftermath of the hurricane but also the historical development of the city both socially and materially. And Ignaz Strebel and Jane Jacobs's study of construction standards for mass housing in the United Kingdom shows how building codes are used to translate global ideas of modern living into local practices of construction and habitation.

The main difference, of course, between the production of novelty in the natural science laboratory and the urban laboratory is that in the latter the boundary conditions can only be controlled to a very limited extent. This is often taken to be a fundamental objection to applying the experimental method to society, but Matthias Gross and 
Wolfgang Krohn invert and radicalize this critique and argue that this actually suggests broadening the notion of experiment beyond the laboratory to encompass society as such: '[t]he experimental nature of society, understood in this way, changes from an evolutionary process [...] into an institutionalized strategy which includes all kinds of political, cultural, or aesthetic components' (2005: 77). Considering that experimentation has become a societal endeavour in which the researcher is simply one actor among others, one conclusion Gross and Krohn draw from this is that the setting of boundary conditions for experiments should be collectively decided. Experimentation, in other words, should become a collective and recursive learning process. In a recent article, Gross (2009) discusses the work of the social reformer, founder of the Hull House settlement and sociologist Jane Addams to illustrate this point. Although related to the Chicago School of sociology, Addams rejected the objectivity of the laboratory and embraced the situatedness of both knowledge production and researcher: '[ $t$ ]he development of settlement houses embedded in the modern city was understood as an experimental performance, with the social worker partaking in the experiment as an observer and occasionally as an intervening actor' (83).

Addams's emphasis on intervention leads to the second achievement of urban laboratories, change-orientation, or what Park described as processes leading to a 'new rule of conduct' and a 'new definition of the situation' (1929: 17). While all places change over time, the urban laboratory is conceived for change that is intentionally radical - change that leads to ontological novelty - rather than incremental or entropic. Laboratory advocates express an explicit dissatisfaction with 'urban development as usual' approaches. The bounded character of the laboratory allows for experimentation at an achievable scale and in a particular locale that has been selected because of its opportunities for success or because of the desperate need for different conditions. Thus, there is a strong normative aim of urban laboratories in creating more desirable futures.

Evans and Karvonen's urban laboratory in Manchester responds to the call for reduced carbon footprints in cities and the equally urgent pursuit of long-term economic development. In the water supply networks in Bengalaru, Gopakumar examines the transformation from pre-modern autonomous to modern networked conditions through a transition that is contested rather than smooth. Dorstewitz's transformation of Zollverein from an abandoned industrial facility into a world renowned cultural facility involves a tricky process of reinterpreting and reworking a local heritage site to create a new narrative for the city. In Allen's green building laboratory in New Orleans, non-local actors recognise an opportunity in the postdisaster landscape to enact global notions of sustainable urban development that conflict with local ideas of culture and place. And Strebel and Jacobs's study emphasises how the UK agenda of modern living is fuelled by notions of mass production and the creation of building standards. In all of these cases, the laboratory is not simply about experimenting but about realising new conditions on the ground that are markedly different from existing conditions.

A third achievement of urban laboratories is the embrace of contingency and uncertainty. Following on the interpretation of urban laboratories as collective learning 
processes with contingent boundaries, the level of uncertainty and the possibility for failure increases. Experiments are thus understood to be contingent and open-ended, carrying substantial risks as well as rewards. Real world experimentation is founded on the idea that one is compelled to act despite uncertainties and gaps in knowledge. This emphasis on action over certainty and recursive learning is closely related to American Pragmatism; indeed, John Dewey was influential in both the Hull House work as well as the Chicago School (Dewey, 1975; Gross, 2010; Hickman, 2007; Jones, 2008). In this sense, urban laboratory actors embrace the complexity and fluidity of urban change processes, recognising that unanticipated outcomes are to be expected and that these outcomes provide new opportunities for learning. Acknowledging uncertainty has become almost obligatory in STS as well social theory (Nowotny et al., 2001; Pellizzoni, 1999; Wallerstein, 2004; Wehling, 2001) but it is striking how little this is discussed in urban studies. Notable exceptions include Patsy Healey's (2006; 2009) collaborative planning approach, Ali Madanipour's (2010) exploration of contingency and planning, and John Abbot's (2005) review of the role of uncertainty in planning.

The contributions to this symposium issue grapple with the indeterminacy and risk of urban laboratories. In the low carbon urban laboratory in Manchester, the emphasis on gathering and analysing real time data highlights the importance of learning in policy making processes. The seemingly straightforward activity of modernisation through the rollout of water supply infrastructure in Bengalaru is complicated by unanticipated activities of informal actors who counter the work of formal actors. The iterative planning process to redevelop Zollverein is a recursive problem-solving endeavour that continually negotiates the competing demands of the project rather than emphasising a conventional, static master plan. In New Orleans, the mix of local and non-local actors in green building activities creates multiple trajectories of change rather than a single conception of the sustainable city. And the seemingly fixed design standards for mass housing in the UK are open to interpretation and subversion by construction and occupation practices.

The situated, change-oriented, and contingent achievements of urban laboratories make them distinct from other forms of urban development. They are intentional sites of urban innovation with both local and global implications. The emphasis on experimentation opens up urban development to new trajectories, storylines, and consequences but the outcomes of these endeavours are far from certain. Thus, urban laboratories should be treated with a healthy combination of curiosity and scepticism, and like any form of urban development, should be subjected to detailed analysis and critique.

\section{Conclusions}

The articles that comprise this symposium demonstrate the multiple ways that urban laboratories are influencing the development of cities, offering insights that cut across conventional notions of urban development and suggesting the need to embrace uncertainty and risk. Most importantly, laboratories recognise that cities are always 'in the making', on the move, and fluid (Guy, 2009); they are active rather than static, championing process over product. At the same time, urban laboratories are perhaps less special than advertised; they simply constitute one type of knowledge production 
amidst many others. They are worthy of study because of the ways in which they strategically negotiate the boundary between inside and outside through the channelling of actors, data, and resources. Through experiments, relations are established between the local and the non-local, between the contingency of a particular laboratory site and the universality of concepts and theories. Many of these lines are investigated in more depth in the articles that follow this introduction, but obviously a number of ideas have been raised that might be explored in future studies of urban laboratories.

First, the notion of scale is of central importance to urban laboratories. Considering our normative focus on the urban laboratories as situated, we recognise the local scale as the key place because actors need to meet face-to-face, exchange tacit knowledge, and take collective action. But is a laboratory confined to a particular neighbourhood or can it extend to a city or even a region and if so, what is lost with increasing complexity? Can we still experiment at 'scale one' as Latour (2001) writes when we attempt to embrace larger and larger areas? Second, our review of the STS laboratory studies tradition has emphasized its limited acknowledgement of institutional elements that shape the very knowledge produced in and through laboratories in the first place. To avoid an overly optimistic and idealistic view of experimentation, there is a need to investigate in more depth how urban laboratories deal with obduracy and the sedimentation of both social and physical infrastructures that resist radical change (Hommels, 2005). Third, the argument that urban laboratories are local as well non-local and can be seen to mediate the tensions between contingency and universality chimes with the renewed interest in urban studies concerning the role of comparison (Ward, 2010). Comparison relies on particular techniques of data collection, strategies of abstraction, and use of concepts and theories quite similar to the activities occurring in urban laboratories. And finally, the loosening of how cities develop suggests that the ways in which knowledge about cities is debated and deployed needs to change radically. The Chicago School's understanding of laboratories connects most obviously to the tradition of American Pragmatism, but ideas of collective and recursive learning also resonates with ideas of participatory, deliberative or radical democracy, and the right to the city.

\section{References}

Abbott, J. (2005) Understanding and managing the unknown: the nature of uncertainty in planning. Journal of Planning Education and Research, 24.3, 237-251.

Associated Press (2008) Pollution curbs turn Beijing into urban laboratory, accessed from

<http://www.thefreelibrary.com/Pollution+curbs+turn+Beijing+into+urban+laborat ory-a01611596585> on14 January 2011.

Beck, U. (1995 [1988]). Ecological politics in an age of risk, Polity Press, Cambridge.

Benneworth, P. (2010) Building localized interactions between universities and cities through university spatial development. European Planning Studies, 18.10, 16111629.

Brand, R. (2005) Urban infrastructures and sustainable social practices. Journal of Urban Technology, 12.2, 1-25. 
Cantor, G. (1989) The rhetoric of experiment. In D. Gooding, T. Pinch, and S. Schaffer (eds) The uses of experiment: studies in the natural sciences, Cambridge University Press, Cambridge.

Collins, H. M. (1985) Changing order: replication and induction in scientific practice, Sage, London.

Davies, G. (2010) Where do experiments end? Geoforum, 41.5, 667-670.

Dewey, J. (1975[1937]) Experience and education, Collier, New York.

Doing, P. (2008) Give me a laboratory and I will raise a discipline: the past, present, and future politics of laboratory studies in STS. In E. J. Hackett, O. Amsterdamska, M. Lynch, and J. Wajcman (eds) The handbook of science and technology studies, third edition, MIT Press, Cambridge, MA.

Evans, J. and A. Karvonen (2011) Living laboratories for sustainability: exploring the politics and epistemology of urban transition. In H. Bulkeley, V.Castán Broto, M. Hodson, and S. Marvin (eds) Cities and low carbon transitions, Routledge, London.

Galison, P. and E. Thompson, E. (eds) (1999) The architecture of science. MIT Press, Cambridge, MA.

Gibbons, M., C. Limoges, H. Nowotny, S. Schwartzman, P. Scott, and M. Trow (1994) The new production of knowledge: the dynamics of science and research in contemporary societies, Sage Publications, Thousand Oaks, CA.

Gieryn, T. F. (2006) City as truth-spot: laboratories and field-sites in urban studies. Social Studies of Science, 36.1, 5-38.

Gieryn T. (2008) Laboratory design for post-Fordist science. Isis 99, 796-802.

Gooday, G. (2008) Placing or replacing the laboratory in the history of science? Isis, 99.4, 783-795.

Gooding, D., T. Pinch, and S. Schaffer (1989) Introduction: some uses of experiment. In D. Gooding, T. Pinch, and S. Schaffer (eds), The uses of experiment: studies in the natural sciences, Cambridge University Press, Cambridge.

Gross, M. (2009) Collaborative experiments: Jane Addams, Hull House and experimental social work. Social Science Information, 48.1, 81-95.

Gross, M. (2010) The public proceduralization of contingency: Bruno Latour and the formation of collective experiments. Social Epistemology, 24.1, 63-74.

Gross, M., and W. Krohn (2005) Society as experiment: sociological foundations for a self-experimental society. History of the Human Sciences, 18.2, 63-86.

Guy, S. (2009) Fluid architectures. In D. White and C. Wilbert (eds), Technonatures, Wilfred Laurier University Press, Ontario.

Hacking, I. (1992) The self-vindication of the laboratory sciences. In A. Pickering (Ed.), Science as Practice and Culture, Chicago University Press, Chicago.

Healey, P. (2006) Collaborative planning: shaping places in fragmented societies, second edition, Palgrave Macmillan, Basingstoke.

Healey, P. (2009) The pragmatic tradition in planning thought. Journal of Planning Education and Research, 28.3, 277-292.

Heathcott, J. (2005) 'The whole city is our laboratory': Harland Bartholomew and the production of urban knowledge. Journal of Planning History, 4.4, 322-355.

Henke, C. R. (2000) Making a place for science: the field trial. Social Studies of Science, 30.4, 483-511.

Henke, C. R. and T. F. Gieryn (2008) Sites of scientific practice: the enduring importance of place. In E. J. Hackett, O. Amsterdamska, M. Lynch, and J. Wajcman (eds), The handbook of science and technology studies, third edition, MIT Press, Cambridge, MA. 
Hess, D. J. (1997) Science studies: an advanced introduction, New York University Press, New York.

Hickman, L. A. (2007) Pragmatism as post-postmodernism: lessons from John Dewey, Fordham University Press, New York.

Hommels, A. (2005) Unbuilding cities: obduracy in urban sociotechnical change. MIT Press, Cambridge.

Jones, 0. (2008) Stepping from the wreckage: geography, pragmatism and antirepresentational theory. Geoforum, 39.4, 1600-1612.

Klein, U. (2008) The laboratory challenge: some revisions of the standard view of early modern experimentation, Isis 99, 769-782.

Knorr-Cetina, K. (1981) The manufacture of knowledge: an essay on the constructivist and contextual nature of science, Pergamon Press, Oxford.

Knorr-Cetina, K. (1995) Laboratory studies: the cultural approach to the study of science. In S. Jasanoff, G.E. Markle, J.C. Petersen, and T. Pinch (eds), Handbook of science and technology studies, Sage Publications, London.

Kohler, R. E. (2002a) Labscapes: naturalizing the lab. History of Science, 40.4, 473-501.

Kohler, R. E. (2002b) Landscapes and labscapes: exploring the lab-field border in biology, Chicago University Press, Chicago.

Latour, B. (1983) Give me a laboratory and I will raise the world. In K. Knorr-Cetina and M. Mulkay (eds), Science observed: perspectives on the social study of science, Sage Publications, London.

Latour, B. (2001) From 'matters of facts' to 'states of affairs'. Which protocol for the new collective experiments?, accessed from <http://www.brunolatour.fr/poparticles/poparticle/P-95\%20MAX\%20PLANCK.html> on 14 January 2011.

Latour, B. (2004) Politics of nature: how to bring the sciences into democracy, Harvard University Press, Cambridge, MA.

Latour, B. and S. Woolgar (1979) Laboratory life: the social construction of scientific facts, Princeton University Press, Princeton, NJ.

Lynch, M. (1985) Art and artifact in laboratory science: a study of shop work and shop talk in a research laboratory, Routledge, London.

Madanipour, A. (2010) Connectivity and contingency in planning. Planning Theory, 9.4, 351-368.

Monstadt, J. (2009) Conceptualizing the political ecology of urban infrastructures: insights from technology and urban studies. Environment and Planning A, 41.8, 19241942.

Nowotny, H., P. Scott, and M. Gibbons (2001) Re-thinking science: knowledge and the public in an age of uncertainty, Polity, Malden, MA.

Park, R.E. (1929) The city as a social laboratory. In T.V. Smith and L.D. White (eds), Chicago: an experiment in social science research, University of Chicago Press, Chicago.

Pellizzoni, L. (1999) Reflexive modernization and beyond: knowledge and value in the politics of environment and technology. Theory, Culture \& Society, 16.4, 99-125.

Pickering, A. (1984) Constructing quarks: a sociological history of particle physics, University of Chicago Press, Chicago.

Pinch, T. (1986) Confronting nature: the sociology of solar neutrino detection, Reidel, Dordrecht.

Radder, H. (1996) In and about the world: philosophical studies of science and technology, State University of New York Press, Albany, NY. 
Radder, H. (2006) The world observed/the world conceived, University of Pittsburgh Press, Pittsburgh, PA.

Ramadier, T. (2004) Transdisciplinarity and its challenges: the case of urban studies. Futures, 36.4, 423-439.

Shapin, S. and S. Schaffer (1985) Leviathan and the air pump: Hobbes, Boyle, and the experimental life, Princeton University Press, Princeton, NJ.

Sismondo, S. (2004) An introduction to science and technology studies, Blackwell, Oxford.

Traweek, S. (1988) Beamtimes and lifetimes: the world of high energy physics, Harvard University Press, Cambridge, MA.

van Heur, B. (2010) Beyond regulation: towards a cultural political economy of complexity and emergence. New Political Economy, 15.3, 421-444.

Wallerstein, I. (2004) The uncertainties of knowledge, Temple University Press, Philadelphia.

Ward, K. (2010) Towards a relational comparative approach to the study of cities. Progress in Human Geography, 34.4, 471-487.

Wehling, P. (2001) Jenseits des wissens? wissenschaftliches nichtwissen aus soziologischer perspektive. Zeitschrift für Soziologie, 30.6, 465-484.

i Key laboratory studies include Collins, 1985; Knorr-Cetina, 1981; Latour and Woolgar, 1979; Lynch, 1985; Pickering, 1984; Pinch, 1986; Shapin and Schaffer, 1985; and Traweek, 1988. For an overview and critique of the literature, see Doing, 2008; Hess, 1997; and Sismondo, 2004. 